em Educação Física) - Faculdade de Educação, Universidade Federal de Goiás.

OLIVEIRA, Dalila, A. Educação básica: gestão do trabalho e da pobreza. Petrópolis: Vozes, 2000.

PORTO, Y. S. Formação continuada: a prática pedagógica recorrente. In: MARIN, A. J. Educação continuada. Campinas: Papirus, 2000.

SOARES, C. L. Educação física: raízes européis e Brasil. Campinas: Autores Associados, 1994.

TAFFAREL, C. N. Z. et al. A educação física escolar na perspectiva para o século XXI. In: MOREIRA, W. W. (Org.). Educação física \& esportes: perspectivas para o século XXI. Campinas: Papirus, 1993. 



\section{A LITERATURA INFANTIL NO BRASIL: POSSIBILIDADES FORMATIVAS ${ }^{1}$}

Rúbia de Cássia Oliveira

\section{RESUMO}

Este artigo aborda questões relativas à literatura infantil e suas possibilidades formativas, visando a pôr em questão as contradições presentes já na origem histórica desse gênero: sua pretensão literária, sua vinculação com a pedagogia, sua vocação autoritária, sua condição de mercadoria e suas possibilidades de formação, humanização e emancipação. De acordo com Marisa Lajolo, Regina Zilberman e Lígia Cademartóri Magalhães, autoras cujas produções sustentam a discussão aqui realizada, a literatura infantil pode contribuir para uma formação voltada para a autonomia desde que apresente uma construção de fato literária.

Palavras-chave: literatura infantil, indústria editorial, pedagogia, formação.

Foi na França do século XVII que surgiram as primeiras obras apropriadas ao público infantil, ${ }^{3}$ mas somente em meados do século XVIII, na Inglaterra, é que apareceram as primeiras publicações destinadas a crianças. Ainda assim, a partir do século XIX é que se pôde observar a consolidação do gênero literário infantil: pelo veio das histórias fantásticas, os Contos (1833), de Hans Christian Andersen, Alice no país das maravilhas (1863), de Lewis Carrol, Peter Pan (1911), de James Barrie, entre diversos outros; como histórias de aventura, $O$ último dos moicanos (1826), de James

\footnotetext{
${ }^{1}$ Artigo recebido em 13/4/2003 e aprovado em 20/5/2005.

2 Mestre em Educação Brasileira pela FE/UFG, Professora Substituta de Psicologia da Educação/FE/UFG. [e-mail: rubia17@ig.com.br]
} 
Cooper, Cinco semanas num balão (1863), de Júlio Verne, apenas para citar alguns exemplos. Esses, juntamente com outros grandes nomes, confirmaram "a literatura infantil como parcela significativa da produção literária da sociedade burguesa e capitalista", dando-lhe "consistência e um perfil definido, garantindo sua continuidade e atração" (LAJOLO, 1988, p. 21).

De acordo com Marisa Lajolo, os livros de literatura para crianças chegaram ao Brasil no século XIX. Com a implantação da Imprensa Régia, em 1808, alguns clássicos europeus foram publicados aqui, mas essas publicações tinham, até então, um caráter esporádico. Somente a partir do início do século XX, com o processo de urbanização e modernização da sociedade brasileira, é que começou a se constituir uma literatura infantil nacional; com o desenvolvimento urbano-industrial, a formação das camadas sociais médias urbanas e o desenvolvimento do sistema de ensino brasileiro é que se formou o público para o gênero literário infantil:

este [o público] é favorável, em princípio, ao contato com livros e literatura, na medida em que o consumo desses bens espelha o padrão de escolarização e cultura com que esses novos segmentos sociais desejam apresentar-se frente a outros grupos, com os quais buscam ou a identificação (no caso da alta burguesia) ou a diferença (os núcleos humildes de onde provieram). (LAJolo, p. 27)

No início do século XX, no contexto dos "apelos nacionalistas e pedagógicos", a produção de títulos brasileiros intensificou-se. No esforço de modernização, a sociedade brasileira investiu na leitura como instrumento fundamental no processo de formação do cidadão. A literatura representou uma via de acesso à modernização, como sugere o conjunto das obras de Monteiro Lobato. Este publicou em 1921 o livro Narizinho arrebitado, dando continuidade a uma série de histórias como O saci (1921), O poço do Visconde (1937), O pica-pau amarelo (1939), Os doze trabalhos de Hércules (1944), entre outros, em que o sítio, porta de entrada e de saída para todas essas aventuras, era a expressão metafórica do Brasil em sua meta de modernizar-se. O sentido de modernização nessas obras pode ser observado na busca de conciliação do nacionalismo (o sítio representa 
o Brasil rural, e Lobato valorizou a cultura brasileira, o que pode ser observado pela criação de personagens como o Saci, a Cuca etc.) com a equiparação cultural do Brasil às grandes potências ocidentais (daí o autor trazer para o sítio diversos personagens literários representantes da cultura ocidental).

O sítio não é apenas o cenário onde a ação pode transcorrer. Ele representa igualmente uma concepção a respeito do mundo e da sociedade, bem como uma tomada de posição a propósito da criação de obras para a infância. Nessa medida, está corporificado no sítio um projeto estético envolvendo o Brasil - e não apenas a reprodução da sociedade rural brasileira. (LAJOLO, p. 56)

Diversos críticos e romancistas "compartilharam a evolução da literatura infantil brasileira, embora de modo diferenciado": José Lins do Rego, com Histórias da velha Totônia (1936); Graciliano Ramos, com Alexandre e outros heróis (1944); Érico Veríssimo, com Os três porquinhos pobres (1936), entre outros. Entretanto, Monteiro Lobato é a maior referência na história da literatura infantil brasileira. Além do caráter literário de suas obras, teve uma atuação importante na constituição do mercado editorial brasileiro:

Tampouco os editores ficaram insensíveis ao novo filão que se abria para seus negócios, inevitavelmente magros num país de tantos analfabetos. Começaram a investir no setor infantil e escolar, a ponto de mais tarde Monteiro Lobato, procedendo de forma semelhante à frente da Companhia Editora Nacional, justificar o segundo plano da literatura em suas publicações. (LAJOLO, 1988, p. 29)

A partir de então, Lobato, já escritor famoso, passa a correr numa outra faixa: investe progressivamente na literatura para crianças, de um lado como autor, de outro como empresário, fundando editoras, como a Monteiro Lobato e Cia., depois a Companhia Editora Nacional e a Brasiliense, e publicando os próprios livros. (LAJoLo, 1988, p. 46)

Na qualidade de empresário, Lobato participou, através da estratégia de distribuição gratuita de livros às escolas, do processo de 
instauração do ambiente escolar como entreposto entre a indústria e a sociedade. Esse processo foi fundamental para a expansão econômica do setor.

A indústria editorial brasileira representa atualmente um importante setor da economia. O subsetor denominado "didáticos", que inclui os paradidáticos e literários, tem um peso significativo em seu faturamento total: de acordo com dados citados por Maria das Graças Monteiro de Castro, essa participação chega a 55\% (CASTRO, 1998, p. 12). Aqui, a relação entre a indústria de livros e a escola é, inclusive, favorecida pelas políticas educacionais, o que confirma, de um modo brasileiro, a origem histórica do objeto em questão.

Com o intuito de ampliar o mercado de consumo dos livros infantis, o que se deu sob o signo de divulgação do livro e de estímulo à leitura, a indústria livreira empreendeu, com o apoio do governo federal brasileiro, diversos esforços no sentido de inserir os livros infantis no ambiente escolar. A par de que essa inserção data do próprio surgimento do gênero, tal política foi intensificada nas décadas de 1970, 1980 e 1990. Esse fato ampliou a absorção da literatura infantil pelas escolas, resultando num encurtamento de sua dimensão literária, na medida em que tais livros passaram a assumir, tanto na forma quanto no conteúdo, características e funções didáticas.

No início da década de 1970, com a promulgação da Lei de Diretrizes e Bases da Educação Nacional, Lei n. 5.692/71, teve início um programa governamental de distribuição de livros no âmbito das escolas públicas brasileiras; esses eram didáticos, inicialmente, expandindo-se posteriormente aos livros de literatura infantil. A LDB/71 institucionalizou a utilização dos livros de literatura infantil no contexto escolar, como recurso pedagógico. Nesse período, surgiram outros nomes que se tornariam referência no setor, como Ana Maria Machado, Ruth Rocha, Ziraldo, Joel Rufino e diversos outros.

Portanto, a influência do Ministério da Educação e Cultura (MEC), inicialmente restrita ao livro didático, passou, na década de 1990, a estender-se aos chamados paradidáticos. Ocorre que a prescrição inicial da Lei n. 5.692/71, de adoção de obras literárias pelas escolas, foi modificada pela LDB de 1996, que considera 
todo e qualquer tipo de texto [...] [como] unidade de ensino. De sorte que o texto literário é tratado em sua especificidade, ressaltando-se a necessidade de incorporá-lo às práticas cotidianas da sala de aula, como uma forma específica de conhecimento, conforme se lê nos parâmetros da língua portuguesa [...]. (LDB, p. 38)

Desse modo, a nova orientação para a utilização do texto literário na escola, emanada dos Parâmetros Curriculares Nacionais, os PCNs, decorrentes da LDB/96, promoveu a intensificação dos paradidáticos, institucionalizando-os como instrumento de ensino e, de certo modo, propondo a substituição dos livros literários pelos paradidáticos. Os PCNs normatizaram "todo e qualquer livro" como instrumento de ensino, de modo que a recomendação passou a se dar no sentido de tratar o texto literário "em sua especificidade, ressaltando-se a necessidade de incorporá-lo às práticas cotidianas da sala de aula", ${ }^{4}$ conforme ressalta Castro:

A questão do ensino de literatura ou da leitura literária envolve [...] esse exercício de reconhecimento das singularidades e das propriedades compositivas que matizam um tipo particular de escrita. Com isso, é possível afastar uma série de equívocos que costumam estar presentes na escola em relação aos textos literários, ou seja, tratá-los como expedientes para servir ao ensino de boas maneiras, dos hábitos de higiene, dos deveres do cidadão, dos tópicos gramaticais [...]. Postos de forma descontextualizada tais procedimentos pouco ou nada contribuem para a formação de leitores capazes de reconhecer as sutilezas, as particularidades, os sentidos, a extensão e a profundidade das construções literárias. (LDB, p. 38)

As estratégias para a inserção cotidiana do livro infantil nas escolas geraram questões de suma importância para a educação no Brasil, entre as quais merecem destaque a instituição do espaço escolar como entreposto entre o público consumidor e a indústria editorial e a criação de um novo gênero "literário" - os paradidáticos. Estes se, por um lado, "resolvem" certos "problemas" gerados por algumas obras literárias que muitas vezes se tornam indesejáveis aos padrões, 
normas e valores da sociedade, por outro, claro está que o seu valor estético e emancipatório é fortemente atenuado por sua condição não-literária.

É exatamente em função desse compromisso original com a pedagogia que os livros para crianças foram "exilados" do campo literário não infantil. De acordo com Lajolo, as histórias da literatura brasileira não incluem a literatura para crianças em seu campo de estudo. Esse não-reconhecimento decorre de algumas características do gênero que, além de se constituir originariamente como instrumento e como mercadoria, tem uma posição historicamente subsidiária em relação à educação e à escola. Por ser caudatária desta e do mercado livreiro, desperta a desconfiança da teoria literária não infantil, culminando no alijamento da primeira do campo de estudo da segunda.

As condições históricas e sociais em que surge e se desenvolve a literatura infantil foram as da Revolução Industrial, fato que determinou as características adotadas pelo gênero. Ao se consolidar como classe social, a burguesia, buscando evitar conflitos violentos como a Revolução Francesa, incentivou o fortalecimento de instituições que pudessem auxiliá-la, por meios mais pacíficos ou cuja violência fosse menos visível na conquista das metas estabelecidas. A família foi uma dessas instituições; além de estabilizar a divisão social do trabalho, converteu-se, pela via dos estereótipos, na "finalidade existencial do indivíduo" (LaJolo, 1988, p. 17). Foi nesse contexto que se consolidou o sentimento moderno de infância, isto é, a forma que esta assume nos tempos atuais, como alvo de interesse e atenção dos adultos e, também, da indústria.

No mundo feudal, a infância não existia como modo de ser específico, como lugar social distinto do dos adultos. As crianças se socializavam junto com estes: trabalhando, presenciando os processos naturais da vida, como o nascimento e a morte, e mesmo participando de atividades como guerras, execuções públicas etc. Desse modo, não havia necessidade de disciplinas ou ciências específicas como a pedagogia, a psicologia e a pediatria, nem de instrumentos educativos como os brinquedos e os livros infantis. A organização social feudal possibilitava um tipo de socialização espontânea, por assim dizer; as crianças tinham uma relação direta com a realidade, as mediações do 
adulto não tinham o caráter e a intensidade que têm hoje, sobretudo através da escola. Da mesma forma, a mãe não tinha a importância que passou a assumir na família burguesa.

A família nuclear patriarcal, sucedâneo burguês do sistema de linhagens e clientela feudal, tornou-se a grande aliada do Estado moderno, servindo-lhe de sustentáculo. Propagou-se a ideologia familista, voltada para o desenvolvimento da privacidade e para a valorização do indivíduo, a partir da infância. Nas camadas sociais abastadas, os cuidados que as crianças recebiam anteriormente pelas amas-de-leite e preceptores foram intensificados e transferidos para a mãe e para a instituição escolar que inicialmente se abriu apenas aos filhos da nobreza e da aristocracia.

Na classe trabalhadora, o processo de constituição da família nuclear foi mais lento, por várias razões. Primeiramente, porque até um certo momento da expansão industrial, as crianças ocupavam boa parte dos empregos disponíveis, por representarem mão-de-obra mais barata. Além desse fator, havia uma série de problemas sociais que, sob a administração burguesa, passaram a assumir uma configuração diferente: com a finalidade de conter o desemprego, dispersar os movimentos políticos fortalecidos pelos contingentes de adultos desempregados e formar a futura mão-de-obra para a indústria crescente, a escolarização obrigatória foi estendida às crianças trabalhadoras.

Além de equacionar esses problemas, a criação da escola possibilitou o êxito do processo de nuclearização da família e solucionou um outro problema gerado pelo isolamento em que a criança passou a viver: "se a configuração da família burguesa leva à valorização dos filhos e à diferenciação da infância enquanto faixa etária e social", esta passou a uma condição de isolamento do mundo adulto e da realidade social. Nesse contexto é que a escola assumiu a função de restaurar a unidade perdida, entre a criança e o mundo (ZILBERMAN, 1982, p. 9).

Assim como a família, e numa relação de cumplicidade com esta, "a escola se qualifica como espaço de mediação entre a criança e a sociedade, o que mostra a complementaridade entre essas instituições e a neutralização do conflito possível entre elas" (LAJOLO, 
1988, p. 17). A literatura infantil surge, nesse contexto, como instrumento a ser utilizado pela escola, visando a uma formação moral e intelectual consonante à ideologia familista.

Os laços entre a literatura e a escola começam desde este ponto: a habilitação da criança para o consumo de obras impressas. Isto aciona um circuito que coloca a literatura, de um lado, como intermediária entre a criança e a sociedade de consumo que se impõe aos poucos; e, de outro, como caudatária da ação da escola, a quem cabe promover e estimular como condição de viabilizar sua própria circulação. (LAJOLO, 1988, p. 18)

O gênero literário infantil, portanto, se constituiu com as marcas desse período, assumindo, desde essa época, a condição de mercadoria e revestindo-se de uma certa instrumentalidade. Zilberman aponta o fato de que na literatura infantil sempre houve uma predominância das motivações educativas sobre as literárias, "não apenas porque provê textos a esta nova faixa, mas porque colabora na sua dominação, ao aliar-se ao ensino e transformar-se em seu instrumento". Contudo, por não abandonar a pretensão literária, esse gênero apresenta uma "duplicidade congênita", pois,

de um lado, percebida sob a ótica do adulto, desvela-se sua participação no processo de dominação do jovem, assumindo um caráter pedagógico, por transmitir normas e envolver-se com sua formação moral. De outro, quando se compromete com o interesse da criança, transforma-se num meio de acesso ao real, na medida em que lhe facilita a ordenação de experiências existenciais, através do conhecimento de histórias, e a expansão de seu domínio lingüístico. É esta duplicidade que assinala sua limitação, gerando o desprestígio perante o público adulto, já que este não admite o legado doutrinário que lhe transfere. (ZILBERMAN, 1982, p. 14)

Essa duplicidade é uma conseqüência do isolamento da criança no seio da família, e esses dois fatores repercutem na produção do livro infantil, pois há uma desigualdade entre o mundo-adulto-produtorde-histórias-para-crianças e o público-infantil-receptor. $\mathrm{O}$ fato de ser produzido e administrado pelo adulto delineia uma assimetria, isto é, uma situação de 
desigualdade entre os comunicadores, estando de um lado o autor adulto e de outro o leitor infantil. Ela diz respeito à situação lingüística, cognitiva, ao status social, para mencionar os pressupostos mais importantes da desigualdade. $\mathrm{O}$ emissor deve desejar conscientemente a demolição da distância preexistente, para avançar na direção do recebedor. Todos os meios empregados pelo autor para estabelecer uma comunicação com o leitor infantil podem ser resumidos sob a denominação de adaptação. (citado por ZiLBERMAN, 1982, p. 18)

Por mais que o autor tente se adaptar ao universo infantil, há uma unilateralidade, observada através da presença onipotente e da determinação do adulto em todo o processo. Este tenta superar as condições assimétricas, indo ao encontro da criança, mas a tentativa de reproduzir a condição do pequeno leitor "converte o texto numa impostura, que repercute no enfraquecimento da forma artística, justifica a acusação de simulacro ou pseudoliteratura e legitima o descrédito" (Zilberman, 1982, p. 19). A única possibilidade de superação da assimetria se dá através da abertura da narrativa ao diálogo com o pequeno leitor. Ao possibilitar sua entrada no texto, conferindo-lhe autonomia de interpretação, a obra equaciona as posições do adulto e da criança.

As narrativas de orientação pedagógica confirmam a tradição adaptativa da educação. Suas metas consistem, como nos aponta Magalhães, em formar o sujeito, favorecer o seu desenvolvimento e transmitir conhecimentos. O sujeito da educação aparece, portanto, como um sujeito ideal, e é essa determinação que engendra o caráter exemplar das histórias elaboradas com a finalidade de educar. A exemplaridade surge como meio de superar a peculiaridade formativa da literatura que, segundo Antonio Candido, educa como a própria vida, com suas luzes e sombras.

Para esse autor, a literatura não é uma experiência necessariamente edificante, segundo os critérios valorativos vigentes. Ela humaniza como a própria vida, com sua complexidade e suas contradições, apresentando, portanto, um caráter não-doutrinário, não-didático. Nessa perspectiva, a utilização da literatura como instrumento pedagógico conduz a pelo menos dois equívocos: adotar como literatura 
o que não é literatura; e adotar com finalidades didáticas o que está para além dos instrumentais pedagógicos, pois é "imagem e transfiguração" da vida e, nesse sentido, "atua segundo a força indiscriminada e poderosa da própria realidade" (CANDIDO, 1989, p. 113).

A literatura "pode formar" não de acordo com a perspectiva oficial do Verdadeiro, do Bom e do Belo, "reforço da sua concepção de vida"; mas "com o impacto indiscriminado da própria vida e educa como ela, com altos e baixos, luzes e sombras". É dessa característica da literatura que decorrem as atitudes ambivalentes dos educadores e das políticas educacionais que, "ao mesmo tempo fascinados pela sua força humanizadora e temerosos de sua indiscriminada riqueza", tentam manipulá-la, proscrevendo-a "como fonte de perversão e subversão" ou assimilá-la "na bitola ideológica dos catecismos" (CANDido, 1972, p. 805).

Por destinarem-se a um sujeito ideal, as histórias comprometidas com a transmissão de normas determinam o lugar do sujeito e, desse modo, impedem que a criança reconheça-se na narrativa, ponto de partida para sua enunciação. Uma narrativa emancipatória não pode submeter-se a isso, mas "neutralizar o absolutismo daqueles que pretendem saber o lugar que a criança deve ocupar" (MAGALHÃES, 1982, p. 53).

O lugar da criança refere-se às suas demandas, ${ }^{5}$ ao processo de construção de sua identidade, à sua construção enquanto sujeito da ação, da cognição, da narrativa, da realidade, do mundo. Como esse sujeito é uma criança, a literatura que se pretenda emancipatória deve superar a desigualdade de origem (assimetria) e, ao invés de reproduzir as imposições da pedagogia, fixando o lugar do sujeito, oferecer-lhe a possibilidade de dizer e se dizer na obra.

Quando a narrativa centraliza-se nas demandas, na trajetória do herói infantil, visando a uma construção literária comprometida com seus dilemas, duas perspectivas abrem-se ao autor da obra: (1) permitir a enunciação do sujeito, através de um "papel" que dê ao personagem certa autonomia em suas vivências, dando-lhe condições de elaborar seus conflitos. Essa opção permite a integração da criança ao texto; ou (2) aprisioná-la, pela repressão de seus processos, conflitos 
e buscas, à tutela dos adultos, assumindo um papel normativo. No primeiro caso, a narrativa oferece possibilidades emancipatórias; no segundo, não.

A enunciação do sujeito (através de personagens ativos, reflexivos, inacabados etc.) e a existência de pontos de indeterminação na narrativa são dois aspectos composicionais fundamentais para que uma obra seja emancipatória. Porque são essas características que possibilitam o diálogo entre o leitor e a obra. Quando os personagens não são construções estáticas, portadoras de formulações e conceitos rígidos do narrador, mas sujeitos que pensam, indagam, sabem ou desconhecem, refletem, buscam ou negam, esses aspectos geram pontos de entrada do leitor no texto. Tal narrativa é emancipatória, pois não determina o lugar do sujeito, ao contrário, reconhece-o como ser ativo ao valorizar seu raciocínio e sua autonomia de interpretação.

A característica acima descrita condiciona-se a um outro recurso técnico empregado pelo escritor: a focalização. As narrativas que se constroem a partir da valorização da palavra do narrador são autoritárias porque se fecham para o diálogo com o leitor. Essa característica pôde ser observada nos 32 títulos objetos da pesquisa realizada no curso de mestrado em Educação Brasileira da Faculdade de Educação da UFG, sobre as possibilidades formativas da literatura infantil. ${ }^{6}$ Só a título de exemplo, Ana Maria Machado, em seu livro Jeca, o Tatu, consegue expressar, através do personagem central, a necessidade da criança de superar seus limites e elaborar sentimentos ou fantasias, como de inferioridade, exclusão etc. Contudo, a forma como o faz revela um recurso narrativo autoritário, pois a narradora diz pela personagem:

Só Jeca, o Tatu, nunca tinha nada para contar. Nunca via nada. Passava o dia todo debaixo da terra e só de vez em quando vinha um pouco até em cima. Mas nunca via nada de interessante. E ficava triste, triste. ${ }^{7}$

Após uma saga de Jeca pela cidade, como resultado de uma série de acontecimentos que revelam seu desejo de superação de um estado de alheamento, ignorância, isolamento, inferioridade etc., ele 
retorna diferente. Se antes ele era ignorado pelos outros bichos, agora todos queriam ouvi-lo:

Todo mundo quer saber mais coisas das aventuras de Jeca, o Tatu. Que nem parece mais o mesmo. Sabe coisas, fala muito, e agora é feliz, feliz.

Esse novo estado, descrito pela narradora, mostra que a personagem elaborou conflitos e superou dificuldades que o distanciavam da realização de seus anseios e demandas. Mas a narração desse processo, autoritária, impede ou dificulta a autonomia de interpretação da criança e, por conseguinte, de suas possibilidades de enunciação.

Se Ana Maria Machado tenta, ainda que de modo autoritário, ser porta-voz de demandas autênticas da criança, Ruth Rocha, por outro lado, imprime a esta as demandas do sistema, o que pode ser observado através, por exemplo, da compulsão de Alvinho, personagem central de uma série de histórias, ao consumo. ${ }^{8}$

Outra forma de autoritarismo dá-se quando o narrador projeta na personagem um modelo para o destinatário; isso acontece com as histórias exemplares.

Um texto que se pretenda emancipador deve centralizar-se na criança, pois uma realização literária supõe a superação da assimetria decorrente da superioridade da produção adulta sobre a recepção infantil (MAGALHÃES, 1982, p. 23). Além disso, se o narrador identificase com a personagem, a transmissão de normas converte-se numa impossibilidade.

O universo ficcional e literário centralizado nas vivências da criança ocasionará lacunas que lhe permitirão dialogar com o texto. E é na escolha dessas vivências, ou seja, do tema, das informações que fazem parte da construção literária e, sobretudo, pelo "código de interpretação" que o autor imprime à obra, que essas vivências serão processos constituídos por ambivalências, contradições etc., permitindo a interpretação da criança - ou modelos impostos ao leitor.

Embora a focalização seja um recurso empregado pelo narrador como "lugar de projeções", este será preenchido por um sujeito real. 
A focalização na personagem é uma condição indispensável para que uma narrativa seja capaz de provocar, em alguma medida, mudanças no leitor: através do rompimento com as modalidades habituais e automáticas da percepção. ${ }^{9}$

Conforme se assinalou acima, um fator determinante quanto ao caráter de uma obra refere-se ao "código de interpretação do mundo", imprimido pelo autor (MAGALHãES, p. 60). Este se manifesta na escolha da informação e na forma de transmiti-la. A narrativa não se exaure com a informação quando permite a construção de conceitos, de saberes que se constituem para além do imediato. Isso possibilita o desenvolvimento de uma consciência histórica, através das interrelações entre o universo focalizado na obra e a realidade histórica.

A esse respeito, Lígia Cademartori Magalhães aprecia a viagem de Dona Benta e seus netos à Grécia Antiga, na qual Lobato, como ocorre de modo geral em suas obras, consegue conciliar informação com formação, didatismo com literatura. É o que se pode observar na discussão estabelecida entre Péricles, Dona Benta e Pedrinho sobre arte:

- Que tal acha estes cavalos, Pedrinho?

- Bons, sim, vovó. São "mangalargas" legítimos - só que têm o focinho muito fino. Os cavalos que eu conheço não são assim.

- Nem os daqui, disse Péricles. Os escultores não reproduzem a natureza tal qual é. Modificam-na num certo sentido, com uma certa intenção. Arte é isso.

- Mas então o belo não é o natural "escarrado", vovó? Perguntou o menino.

- Não, meu filho. Se fosse, os melhores museus do mundo seriam as escarradeiras, e a maior das artes seria a fotográfica. ${ }^{10}$

As narrativas que propiciam relações entre o específico e o geral, entre o passado e o presente, perpassadas de indagações e reflexões, apresentam o caráter prospectivo, descrito por Magalhães:

O critério perante essa característica inerente à obra [de emancipar ou não] é a distinção entre aquelas obras que são apenas eco de 
lugares-comuns estéticos e ideológicos e aquelas que não apenas conservam experiências adquiridas, mas conduzem ao questionamento dos convencionalismos de interpretação e comportamento pela apresentação de novas perspectivas. A obra emancipatória é prospectiva, porque pela amostragem de novas possibilidades propicia experiências futuras; a obra convencional é retrospectiva, porque valida experiências passadas sem redimensioná-las criticamente. (MAGAlHãEs, 1982, p. 54)

Esse aspecto nos remete à formulação de Candido sobre a função total da literatura: sobrepujante nas grandes obras, caracterizase, entre outros aspectos, pela universalidade e intemporalidade. Conforme o autor, essas características estão presentes em obras como a Odisséia, de Homero, escrita há dezenas de séculos e com a qual o leitor de todos esses tempos foi capaz de dialogar e de humanizar-se. Universalidade e intemporalidade são dimensões alcançadas pelo caráter prospectivo de uma obra. ${ }^{11}$

Lajolo chama a atenção para a função formativa da literatura infantil: através da incorporação do universo afetivo e emocional da criança ao texto,

traduz para o leitor a realidade dele, mesmo a mais íntima, fazendo uso de uma simbologia que se exige, para efeitos de análise, a atitude decifradora do intérprete, é assimilada pela sensibilidade da criança. (LAJOLO, 1988, p. 20)

Se, entretanto, o modo como o adulto quer que a criança veja o mundo, expresso pelo autor da obra, negligencia "a expressão simbólica de vivências interiores do leitor". Nesse caso, ao fazer a opção por educar, a obra desmascara-se como doutrinária.

As reflexões aqui desenvolvidas permitem-nos abordar um problema fundamental, relativo à ontologia do gênero em questão: é possível à literatura infantil ser literatura? De acordo com Lajolo, o fato de ser uma literatura para configura uma destinação cujo acento é apenas circunstancial, ou seja, o fato de ser para crianças não pode interferir na dimensão literária do texto. Literatura infantil e não infantil fazem parte de um mesmo processo cultural: "a arte literária circunscreve sempre um espaço próprio e inalienável de atuação, 
embora seja ele limitado por vários fatores" (LAJolo, p. 19). Se é verdade que o elemento gratuidade faz-se menos presente na primeira, isso não a invalida como produção literária. A questão, portanto, concerne mais à qualidade da obra, ou seja, ao fato de se tratar de literatura ou subliteratura, sendo essa classificação válida tanto para as obras destinadas ao público adulto quanto ao infantil.

Conforme se buscou mostrar ao longo desta exposição, Zilberman e Magalhães acreditam que o que se denomina amplamente como literatura para crianças pode ser de fato literatura. Isso se condiciona à existência de aspectos relacionados à enunciação do sujeito na narrativa, à existência de pontos de indeterminação, à construção ficcional focalizada na criança, ou seja, uma série de recursos técnicos cuja manipulação conduzem à enunciação e à emancipação do leitor: "a literatura infantil [...] tem o que oferecer à criança, desde que examinada em relação à sua construção propriamente literária" (ZILBERMAN; MAGALHÃES, 1982, p. 14).

\section{ABSTRACT}

This article approaches issues related to children's literature and its formative possibities, aiming to question the contradictions which were already present in the historical origin of this genre: its literary claim, its links to education, its authoritarian vocation, its condition as merchandise and its possibilities for formation, humanization and emancipation.

According to Marisa Lajolo, Regina Zilberman and Lígia Cademartóri Magalhães, authors whose work support the discussion held here, children's literature can contribute to a formation that focuses on autonomy as long as it is in fact a literary construction.

Keywords: children's literature, publishing industry, pedagogy, formation.

\section{NOTAS}

3. As Fábulas, de La Fontaine, As aventuras de Telêmaco, de Fénelon, e Os contos da mamãe Gansa, de Charles Perrault.

4. A proposta dos PCNs de substituição dos livros literários pelos paradidáticos não contradiz sua recomendação acerca da importância de 
se incorporar os livros literários às práticas cotidianas, porque o processo de inserção da literatura no cotidiano escolar representou a condição ideal para o desenvolvimento da indústria editorial e a concomitante banalização do livro literário infantil.

5. Apesar de as demandas da criança confundirem-se, em grande medida, com as demandas do próprio sistema, e a própria indústria cultural cumprir um papel decisivo nesse processo, há que não se perder de vista o fato de as crianças terem seus próprios anseios, necessidades e demandas.

6. Essa pesquisa foi realizada com 17 títulos de Ruth Rocha e 15 de Ana Maria Machado, as duas autoras mais vendidas no gênero em Goiânia, de acordo com levantamento junto às principais livrarias da cidade. O trabalho consistiu numa discussão dessas obras a partir de um estudo sobre indústria cultural, do conceito de literatura em Antonio Candido e das discussões de Regina Zilberman, Lígia Cademartori Magalhães e Marisa Lajolo acerca das possibilidades formativas da literatura infantil.

7. MACHADO, Ana Maria. Jeca, o Tatu. Rio de Janeiro: Salamandra, 1993. As páginas não são numeradas.

8. Ver ROCHA, Ruth. Alvinho e os presentes de Natal. São Paulo: FTD, 1986.

9. A esse propósito, Jameson assinala a "vocação que tem a arte de reestimular a percepção, resgatar o frescor da experiência do torpor rotineiro e reificado da vida cotidiana" (JAMESON, 1997, p. 141).

10. LOBATO, Monteiro. O minotauro. São Paulo: Brasiliense, 1952, p. 70.

11. Toda a discussão aqui desenvolvida sobre literatura infantil é fundamentada por três autoras: Zilberman, Magalhães e Lajolo. Esta última, não apenas trabalha com as concepções de Candido, como parece ter sido fortemente influenciada por seu pensamento. A postulação acerca do caráter prospectivo de uma obra é realizada por Zilberman e Magalhães, que, em toda sua obra, não fazem uma referência sequer a Candido. Portanto, a aproximação estabelecida entre prospecção versus universalidade e intemporalidade é decorrente de uma interpretação minha.

\section{REFRÊNCIAS}

ARIÈS, Philippe. História social da criança e da família. 2. ed. Rio de Janeiro: LTC, 1981. 
CASTRO, Maria das Graças M. Literatura infantil: livro e mercadoria na pré-escola. Goiânia, 1998. (Mimeo).

CANDIDO, Antonio. Literatura e sociedade. São Paulo: Publifolha, 2000.

. A literatura e a formação do homem. In: Ciência e Cultura. v. 24, n. 9 , set. 1972.p. 803-809.

(Org.). Direitos humanos e literatura. In: Direitos humanos $e$ literatura. São Paulo: Brasiliense, 1989. p. 107-126.

JAMESON, Frederic. Pós-modernismo - a lógica cultural do capitalismo tardio. 2. ed. São Paulo: Ática, 1997.

KANT, Immanuel. Analítica do Belo. São Paulo: Abril, 1974. (Coleção Os Pensadores).

LAJOLO, Marisa; ZILBERMAN, Regina. Literatura infantil brasileira história e histórias. São Paulo: Ática, 1988.

Ana Maria Machado. Literatura comentada. São Paulo: Abril, 1982.

ZILBERMAN, Regina; MAGALHÃES, Lígia Cademartori. Literatura infantil: autoritarismo e emancipação. São Paulo: Ática, 1982. 
